\title{
Strategies for Amplification by Polymerase Chain Reaction of the Complete Sequence of the Gene Encoding Nuclear Large Subunit Ribosomal RNA in Corals
}

\author{
Chaolun Allen Chen, ${ }^{1, \star}$ Carden C. Wallace, ${ }^{2}$ Jr-Kai Yu, ${ }^{1}$ and Nuwei Vivian Wei ${ }^{1,3}$ \\ ${ }^{1}$ Institute of Zoology, Academia Sinica, Nankang, Taipei 115, Taiwan \\ ${ }^{2}$ Museum of North Queensland, Townsville, Queensland Q4810, Australia \\ ${ }^{3}$ Institute of Oceanography, National Taiwan University, Taipei 106, Taiwan
}

\begin{abstract}
The nearly complete nuclear large subunit ribosomal RNA (LSU rRNA) gene in corals was amplified by primers designed from polymerase chain reaction (PCR) strategies. The motif of the putative $3^{\prime}$-terminus of the LSU rRNA gene was sequenced and identified from intergenic spacer (IGS) clones obtained by PCR using universal primers designed for corals. The $3^{\prime}$-end primer was constructed in tandem with the universal $5^{\prime}$-end primer for the LSU rRNA gene. PCR fragments of $3500 \mathrm{bp}$ were amplified for octocorals and non-Acropora scleractinian corals. More than $80 \%$ of the Acropora LSU rRNA gene ( $3000 \mathrm{bp}$ ) was successfully amplified by modification of the $5^{\prime}$-end of the IGS primer. Analysis of the 5'-end of LSU rDNA sequences, including the D1 and D2 divergent domains, indicates that the evolutionary rate of the LSU rDNA differs among these taxonomic groups of corals. The genus Acropora showed the highest divergence pattern in the LSU rRNA gene, and the presence of a long branch of the Acropora clade from the other scleractinian corals in the phylogenetic tree indicates that the evolutionary rate of Acropora LSU rDNA might have accelerated after divergence from the common ancestor of scleractinian corals.
\end{abstract}

Key words: PCR, nuclear, large subunit ribosomal RNA gene, coral, Acropora.

\section{INTRODUCTION}

Eukaryotic ribosomal DNA (rDNA) is composed of tandemly repeated units (Figure 1) containing the coding regions for small subunit (SSU), 5.8S, and large subunit (LSU) ribosomal RNA separated by internal transcribed spacers (ITS1 and ITS2). The transcription units are sepa-

Received February 17, 2000; accepted June 12, 2000.

${ }^{*}$ Corresponding author: telephone 886-2-2789-9549; fax 886-2-2785-8059; e-mail: cac@gate.sinica.edu.tw rated from each other by an intergenic spacer (IGS), which comprises the signals for transcription initiation and termination (reviewed in Gerbi, 1985). Because different regions of the rDNA repeat units evolve at very different rates, phylogenetic analyses of these rDNA sequences provide an opportunity to investigate organismal evolution (reviewed in Hillis and Doxon, 1991). Of these accumulated molecular data (Van de Peer et al., 1994; reviewed in Van de Peer et al., 1997), complete or nearly complete SSU rDNA has been utilized extensively for studies of relationships among all different life forms (Cedergren et al., 1998; Van de Peer et al., 1990), evolution of metazoans (Field et al., 1988; Wain- 


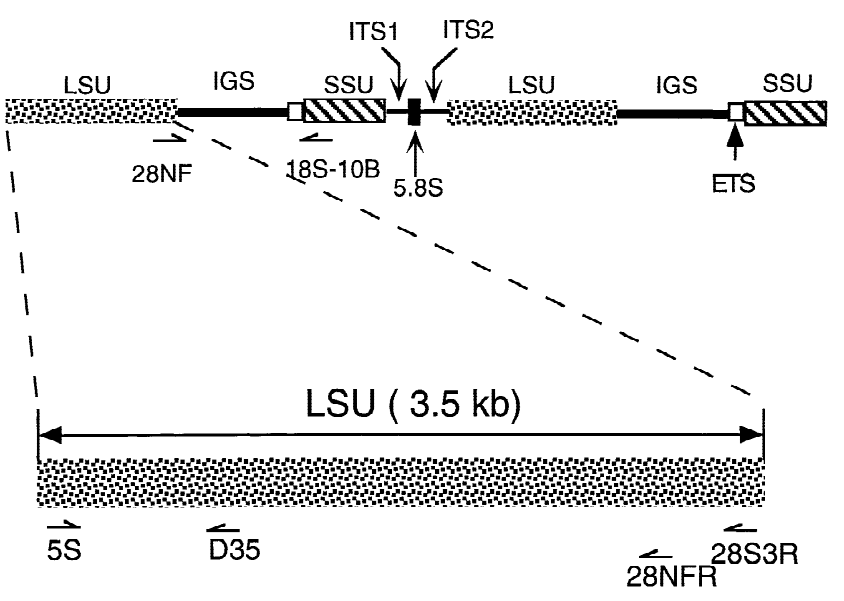

Figure 1. Primer localities and the basic organization of a typical rRNA cistron in a eukaryotic nuclear genome. The coding regions for mature RNA (SSU, 5.8S, and LSU), external transcribed spacer (ETS), intergenic spacer (IGS), and internal transcribed spacers (ITS) are shown.

right et al., 1993; Smothers et al., 1994; Aguinaldo et al., 1997; Kim et al., 1999), and higher hierarchies within a phylum (e.g., Steiner and Müller, 1996; Winnepenninckx et al., 1996; Berntson et al., 1999).

On the contrary, application of complete or nearly complete LSU rDNA sequences to phylogenetic approaches is growing slowly (Zardoya and Meyer, 1996; Mallatt and Sullivan, 1998). The longer chain length of LSU rDNA (>3000 bp) has retarded the acquisition of sequences, and larger differences in length and variability of divergent (D) domains (Hassouna et al., 1984) within LSU rDNA have frustrated attempts to assemble a good alignment of all sequences. Nonetheless, analyses of 225 representative sequences from 38 eukarya, 16 archaea, 64 bacteria, 31 plastids, and 76 mitochondria have been attempted (De Rijk et al., 1995). The comparative conclusions suggest that the impact of the species set on the topology of the resulting consensus tree is much lower using LSU than using SSU rDNA, indicating that LSU rDNA is a better molecule for studying wide-range relationships (De Rijk et al., 1995).

Corals, including soft corals (octocorallians) and hard corals (scleractinians), represent the basal group (i.e., class Anthozoa) in the evolution of the phylum Cnidaria (Bridge et al., 1995; Odorico and Miller, 1997a; Kim et al., 1999). External and internal evolutionary relationships of these two groups have been examined using different molecules, and the results are controversial (Chen et al., 1995; France et al., 1996; Romano and Palumbi, 1996; Veron et al., 1996; Berntson et al., 1999). Analysis of $225 \mathrm{bp}$ of the $5^{\prime}$-end of
LSU rDNA from a variety of anthozoans indicates that Octocorallia is the sister group of Scleractinia, supporting the 3 -subclass relationship (Ceriantipatharia [Ocotocorallia, Scleractinia]) within the class Anthozoa corals (Chen et al., 1995), and a monophyly of scleractinians (Veron et al., 1996). A portion of mitochondrial LSU (16S) rRNA in 29 species of deep sea anthozoans, however, supports a 2-subclass organization (Hexacorallia and Octocorallia) of the class Anthozoa (France et al., 1996). However, analyses of the same segment of mtLSU rDNA sequences in 34 species of scleractinian corals find no support for the current grouping at the suborder level. These results suggest multiple origins of the scleractinian skeleton, and the great diversity of present-day scleractinians may reflect these multiple origins (Romano and Palumbi, 1996, 1997). Although an analysis of a large set of SSU rDNA sequences has recently been attempted for 40 anthozoan species, the limited phylogenetic information in SSU rDNA ultimately confines its application to the higher hierarchy within the class Anthozoa (Berntson et al., 1999). In order to resolve the internal or external evolutionary relationship of corals, it is clear that more sets of comparative molecular data, such as complete LSU rDNA, must be examined.

In the present study we therefore applied polymerase chain reaction (PCR) strategies to (1) identify the motif of the 3 '-terminus of LSU rDNA from several species of corals, (2) redesign the primers to amplify the nearly complete LSU rDNA with a size of over 3000 nucleotides, and (3) reveal the molecular evolutionary pattern of LSU rDNA in corals using the sequences obtained in this study. Analysis of the $5^{\prime}$-end and $3^{\prime}$-end of sequences confirmed the successful amplification of complete or nearly complete LSU rDNA. A preliminary analysis of the $5^{\prime}$-end of LSU rDNA indicated that the evolutionary rate of LSU rDNA apparently differs among the major taxonomic groups of corals, with the genus Acropora showing the highest divergence in the LSU rRNA gene.

\section{Materials and Methods}

\section{Coral Samples}

Taxa, collecting locations, and DNA sources of corals used in the present study are summarized in Table 1. We collected sperm materials of Acropora muricata, A. digitifera, A. cytherea, Echinophyllia orpheensis, Platygyra sinensis, Favia favus, and Favites abdita on nights of predicted coral spawn- 
Table 1. Taxonomic Information, Collecting Locations, and DNA Sources of the Corals Used in This Study

\begin{tabular}{lllr}
\hline Taxon & Collecting sites & DNA source & Identification reference \\
\hline Scleractinia & & & \\
Acropora muricata & Penghu, Taiwan & Sperm & Wallace (1999) \\
Acropora digitifera & Penghu, Taiwan & Sperm & Wallace (1999) \\
Acropora cytherea & Nanwan Bay, Taiwan & Sperm & Vernon and Pichon (1980) \\
Porites cylindrica & Green Island, Taiwan & Tissue & Vernon and Pichon (1980) \\
Pavona catcus & Orpheus Island, Australia & Tissue & Vernn and Pichon (1980) \\
Galaxea fascicularis & Penghu, Taiwan & Sperm & Vernon and Pichon (1980) \\
Echinophyllia orpheensis & Nanwan Bay, Taiwan & Sperm & Veron et al. (1977) \\
Platygyra sinensis & Penghu, Taiwan & Sperm & Veron et al. (1977) \\
Favia favus & Penghu, Taiwan & Sperm & Veron et al. (1977) \\
Favites abdita & Nanwan Bay, Taiwan & Sperm & Tissue \\
Tubastrea aurea & Nanwan Bay, Taiwan & & Vernon and Pichon (1980) \\
Octocorallia & & Tissue & Dai (1989) \\
Junceella fragilis & Green Island, Taiwan & Tissue & Rho and Song (1976) \\
Virgularia juncea & Penghu, Taiwan & & \\
\hline
\end{tabular}

ing in southern Taiwan in 1997 (Dai et al., 1992) and in the Penghu Islands in 1998 and 1999 (C.A. Chen et al., unpublished data). For Porites cylindrica, Tubastrea aurea, Junceella fragilis, and Virgularia juncea, a small fragment on the tip of a coral branch was clipped from each colony and placed in a labeled bag. Both sperm and tissues were frozen in liquid nitrogen or dry ice for transfer to the laboratory. All samples were stored at $-70^{\circ} \mathrm{C}$ prior to analysis. DNA of Pavona catcus was a gift from Dr. David Miller, Department of Biochemistry and Molecular Biology, James Cook University, Australia.

\section{DNA Extraction, Amplification, Cloning, and Sequencing}

DNA extraction was modified from methods described by Chen and Yu (2000). IGS rDNA was initially amplified to determine the approximate position of the 3 '-terminus of the $28 \mathrm{~S}$ rRNA coding sequence. PCR of the IGS rDNA was modified after Smith et al. (1997) and Chen et al. (2000), using the "universal" primer pairs 28NF, 5'-GATTATGACTGAACGCCTCTAAGTCAGAAT CC-3', and 18S-10B, 5' TTACCATCGACAgTtgataggGCAgA-3' (Figure 1). PCR was performed in a PC-9606 thermal sequencer (Corbett Research) using the following thermal cycle: 1 cycle at $95^{\circ} \mathrm{C}$ (1.5 minutes); 4 cycles at $94^{\circ} \mathrm{C}$ (30 seconds), $60^{\circ} \mathrm{C}(1$ minute), $72^{\circ} \mathrm{C}$ (3.5 minutes), and 30 cycles at $94^{\circ} \mathrm{C}(30$ seconds), $57^{\circ} \mathrm{C}$ ( 1 minute), $72^{\circ} \mathrm{C}$ (3.5 minutes). The ampli- fication reaction used 50 to $200 \mathrm{ng}$ of template and BRL Taq polymerase in a $50-\mu \mathrm{l}$ volume reaction using the buffer supplied with the enzyme and under the conditions recommended by the manufacturer. The PCR products were electrophoresed in a $0.8 \%$ agarose (FMC Bioproduct) gel in $1 \times$ TAE buffer to check the yield. The amplified DNA was extracted once with chloroform, precipitated with ethanol at $-20^{\circ} \mathrm{C}$, and resuspended in water. PCR products were cloned using the pGEM-T system (Promega) under the conditions recommended by the manufacturer. The nucleotide sequences were determined for both ends of PCR products of at least 3 clones form each sample using an ABI 377 Genetic Analyzer. (The sequences obtained in this study have been submitted to GenBank under accession numbers listed in the legends to Figures 3 and 5.)

\section{Sequence Alignment and Phylogenetic Analysis}

DNA sequences were initially aligned using CLUSTAL W 1.7 (Thompson et al., 1994), followed by manual editing using SEQAPP 1.9 (Gilbert, 1994). The divergent (D) domains of both ends of $28 \mathrm{~S}$ rDNA sequences in corals were determined by comparing predicted secondary structures to the corresponding rRNA database (De Rijk et al., 1998). In order to examine the molecular evolutionary pattern of LSU rDNA in corals, we performed the following analyses.

First, variability in 60-bp sliding windows plotted throughout the $5^{\prime}$-end of LSU rDNA sequences, including 
the D1 and D2 domains (between 596 bp in Acropora muricata and 772 bp in Galaxea fascicularis), was performed for the 8 taxa using MEGA 1.01 (Kumar et al., 1993).

Second, because size differences in the D2 domain introduced a significant number of gaps for Acropora corals (see Results and Discussion), we analyzed the first $352 \mathrm{bp}$ of eight $5^{\prime}$-ends of LSU rDNA obtained in this study for nucleotide composition differences. Each sequence was examined for nucleotide composition to the frequency distribution assumed in the maximum likelihood model; the transition-to-transversion ratio was estimated from the sequences, and maximum-likelihood (ML) distances were computed under the Hasegawa-Kishino-Yano (HKY) model using the package PUZZLE 4.01 (Strimmer and von Haeseler, 1996).

Third, we aligned the first 205 bp of the $5^{\prime}$-end of LSU rDNA to those of 19 published coral LSU rDNA sequences available in GenBank for phylogenetic inferences. Phylogenetic analyses were performed using the maximumlikelihood and the neighbor-joining methods. The maximum-likelihood analysis, the best suited for modeling the heterogenous substitution pattern, was implemented in the package PUZZLE 4.01. The ML distances and branch lengths were computed under the HKY model (Hasegawa et al., 1985). The neighbor-joining option was performed based on the Kimura 2-parameter distance with among-site rate variation determined using PAUP 4b3.ppc (Swofford, 1999). Robustness of the phylogenies was assessed by the 1000 bootstrap option using neighbor-joining tree construction in PAUP 4b3.ppc.

\section{Results}

The IGS region of the 3 '-end of LSU rDNA was successfully amplified in several coral species (Figure 2) using primers designed from previous studies (Smith et al., 1997; Chen et al., 2000). As evidenced by the general characteristics of the IGS region of rDNA (reviewed in Gerbi, 1985), the sizes of amplified fragments were polymorphic within individuals (e.g., Virgularia juncea and Porites cylindrica in Figure 2) and extremely variable among coral species as a result of the presence or absence of tandem subrepeats within the IGS in several coral species (C.A. Chen et al., unpublished data). In Junceella fragilis, reproduction is dominated by asexual fragmentation (Walker and Bull, 1983; Vermeire, 1994). Sequence analysis of IGS in J. fragilis indicated that only a segment of tetra nucleotide simple sequence repeats, (C[A/

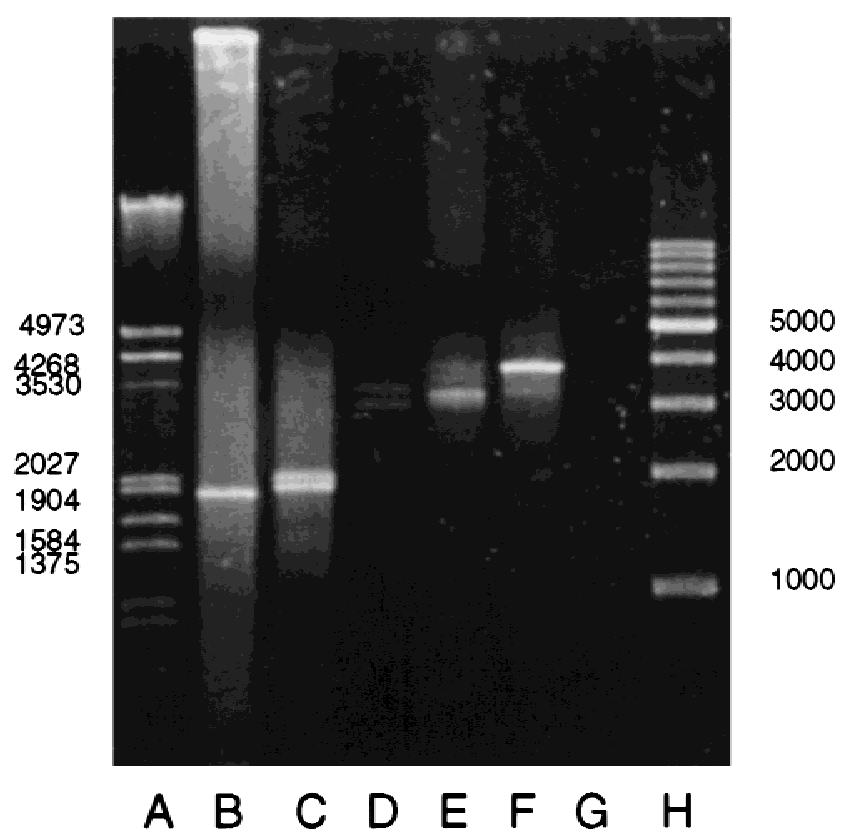

Figure 2. Agarose $(0.8 \%)$ gel electrophoresis of PCR products representing the IGS region from a variety of corals. Lane A, $\lambda$ cut by HindIII and EcoRI, DNA standard size markers; lane B, Junceella fragilis; lane C, Virgularia juncea; lane D, Porites cylindrica; lane E, Favites abdita; lane F, Echinophyllia orpheensis; lane G, negative control; lane $\mathrm{H}, 1-\mathrm{Kb}$ ladder, Waston, DNA standard size marker.

G]GA) , was found in the $5^{\prime}$-end of IGS (Figure 3), and distinctive subrepeats were not observed in the entire region (Chen et al., 2000). The alignment showed a clear line between conserved blocks and the remaining highly variable IGS sequences at $251 \mathrm{bp}$ (Figure 3). The BLAST search in the GenBank and secondary structure comparison indicated that the motif 5'-CTTGTTCTAAGATTTGT-3' represented the putative $3^{\prime}$-terminus of LSU rDNA of corals.

We designated the $3^{\prime}$-end primer of LSU rDNA based on the alignment in Figure 3. The primer 28S3R, in conjunction with the $5^{\prime}$-end primer $5 S$ (Table 2), can successfully amplify the entire region of LSU rDNA for both octocorals and non-Acropora scleractinian corals with PCR products of about $3500 \mathrm{bp}$ (Figure 4). In order to amplify the LSU rDNA of Acropora, the reverse complement of 28NF, 28NFR, was modified (Table 2). Acropora LSU rDNA could be successfully amplified with PCR products of 3000 bp (Figure 4). These results imply that the 3 '-end of Acropora LSU rDNA is probably divergent compared with those of other corals. This high divergence between Acropora and other corals was further revealed by the sequence and phylogenetic analyses of the $5^{\prime}$-end of LSU rDNA (see below). 


Junceella fragilis
Virgularia juncea
Pavona cactus
Tubastrea aurea
Porites cylindrica
Favites abdita
Echinophyllia orpheensis
Junceella fragilis
Virgularia juncea
Pavona cactus
Tubastrea aurea
Porites cylindrica
Favites abdita
Echinophyllia orpheensis

Junceella fragilis
Virgularia juncea
Pavona cactus
Tubastrea aurea
Porites cylindrica
Favites abdita
Echinophyllia orpheensis
Junceella fragilis
Virgularia juncea
Pavona cactus
ubastrea aurea
Porites cylindrica
Favites abdita
Echinophylia orpheensis
Junceella fragilis
Virgularia juncea
Pavona cactus
Tubastrea aurea
Porites cylindrica
Favites abdita
Echinophyllia orpheensis

CTGCTAGAAAGCAACGATC-ATTCC-TCTGGACAATCTTAGGCGAACGAGAATAGAAGC---TTCGG-CTTCCTGCGTCACAATGTGCTAAGGAGCAGAC

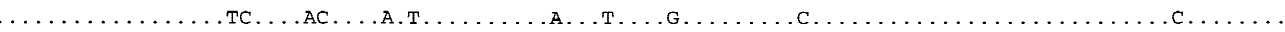

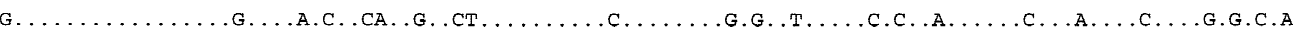

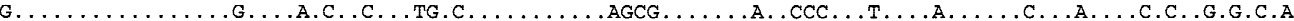

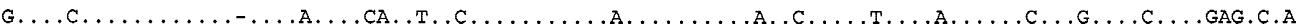

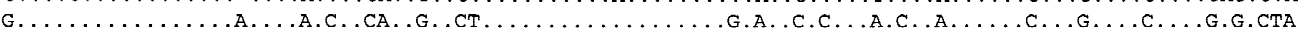

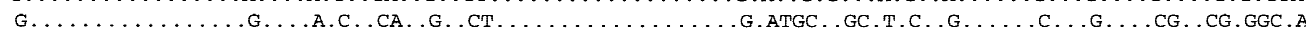
TACGCTC-TGAAGCACTACCTTGACCAAAATCTAAATTTTCCAGAGCTAAATCCTTTGCAGACGACTTAAATAAAGAACGGGGTATTGTAAGCGGTAGAG

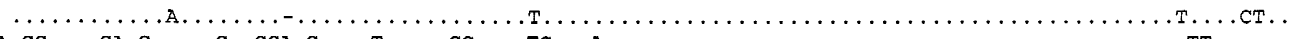

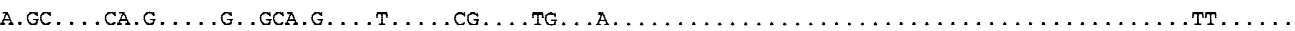

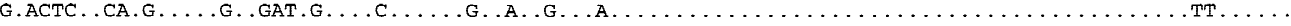

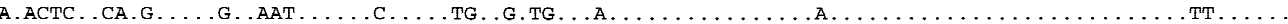

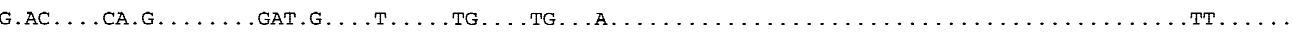

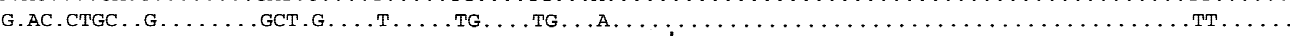
28S3R TAGCCTTGTTGCTACGATCCGCTGAGATTAA\&CCCTTGTTCTAAGATTTGT

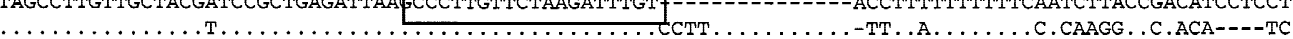

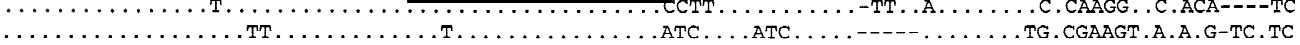

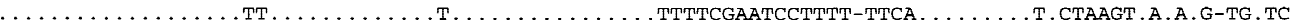

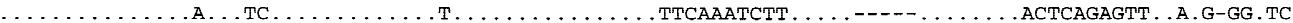

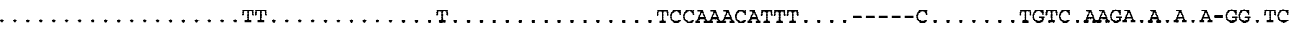

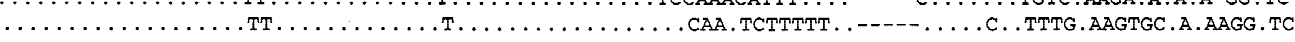
AGTTACCGTCCCTTCGCCTCGTGATGGCTTCGCACAGACGGACAGACGGAGAGACGGACAGACGGACGGACGGACGGACGGACGGACGGACAGACGGACT

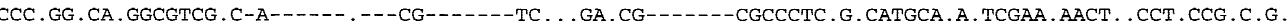
CTC---A. ACCATGAA-A. AT--

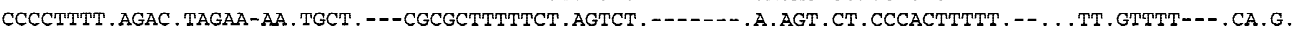
CCC.CTT. --GT-GA . GGG-AGCT--- .--CTTTCA . ACACT . AGTC------CA . A . GACT . CACACT . T . TTTCTT . CTTTTTTTTTT . TA . G .

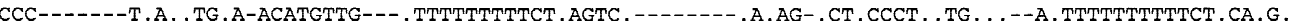
CCC.C.T---. T.G--

ATTGTTT-TCCAAGACCCCGGCATCCTCCAGGGGACCGTCGAC-----ATTCCTCGATATTCTCTTACAACATTCTTGCACGTTTTTTTGCTCTTTTTTI

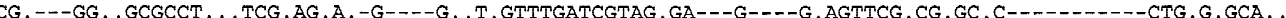

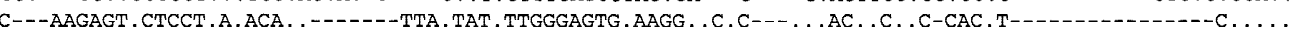

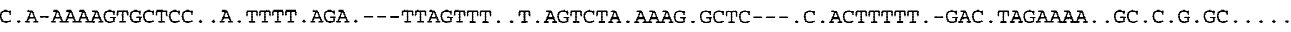

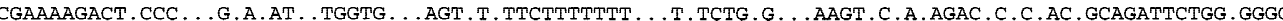

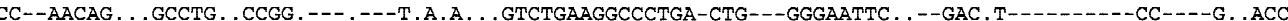

Figure 3. Sequence alignment of the region at the $3^{\prime}$-end of LSU rDNA and parts of the $5^{\prime}$-end of IGS from a variety of corals. Dots indicate identity with the Junceella fragilis sequence, and dashes indicate gaps introduced to optimize the alignment. The putative motif of the 3 '-terminus of the $28 \mathrm{~S}$ rRNA coding sequence and the locality of the primer are indicated by an open box and boldface arrows, respectively. GenBank accession numbers: Junceella fragilis, AF154670; Virgularia juncea, AF263349; Pavona cactus, AF263350; Tubastrea aurea, AF263351; Porites cylindrica, AF263352; Favites abdita, AF263353; and Echinophyllia orpheensis, AF263354.

Table 2. Primer Sequences Used and Designed in This Study

\begin{tabular}{|c|c|c|}
\hline Primer & Sequence & $\begin{array}{l}\text { ion in the } 28 \mathrm{~S} / 18 \mathrm{~S} \\
\text { rDNA of mouse }\end{array}$ \\
\hline $5 S^{*}$ & 5'-GCCGACCCGCTGAATTCAAGCATAT-3' & $21-45$ \\
\hline $28 \mathrm{NF} \ddagger$ & $5^{\prime}$-GATTATGACT GAACGCCTCT AAGTCAGAAT CC-3' & $4331-4352$ \\
\hline $28 \mathrm{NFR} S$ & $5^{\prime}$-GGATTCTGAC TTAGAGGCGT TCAGTCATAA TC-3' & $4331-4352$ \\
\hline $28 \mathrm{~S} 3 \mathrm{R} \S$ & $5^{\prime}$-CAAATCTTAG AACAAGGGCTTAATCTCAG- $3^{\prime}$ & - \\
\hline
\end{tabular}

${ }^{\star}$ PCR primer adapted from Chen et al. (1995).

$\dagger$ Sequencing primer designed in this study.

$\ddagger$ PCR primer adapted from Smith et al. (1997).

§PCR primer designed in this study.

We sequenced and assessed the molecular evolutionary pattern of the $5^{\prime}$-end of PCR fragments. The results indicate that the PCR products we obtained represent the nuclear LSU rDNA of corals. The alignments, including the D1 and
D2 domains, of 8 species of corals are presented in Figure 4. The $5^{\prime}$-end of LSU rDNA of corals showed moderate to high bias of $\mathrm{G}+\mathrm{C}$ contents in their nucleotide composition, ranging from $51 \%$ in D1 of Junceella fragilis to $71.8 \%$ in D2 

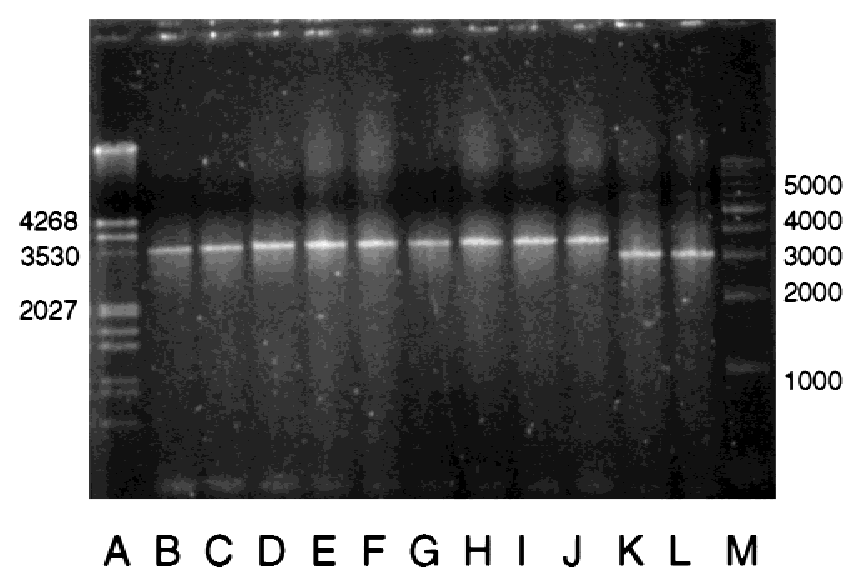

Figure 4. PCR products amplified by $5 \mathrm{~S}$ and 28SFR (lanes B-J) and 28SNFR (lanes K, L) from a variety of corals. Lanes A and M represent DNA standard markers (corresponding with lanes A and $\mathrm{H}$, respectively, in Figure 2). Lane B, Junceella fragilis; lane C, Virgularia juncea; lane D, Pavona catcus; lane E, Porites cylindrica; lane F, Favites abdita; lane G, Echinophyllia orpheensis; lane H, Favia favus; lane I, Platygyra sinensis; lane J, Tubastrea aurea; lane $\mathrm{K}$, Acropora muricata; and lane L, Acropora digitifera.

of Galaxea fascicularis (Table 3). Sequence length ranged from 596 bp in Acropora muricata to 772 bp in Galaxea fascicularis with a similar size of the D1 domain (155-162 bp). However, D2 domains were highly variable in size, with the shortest D2 found in both A. digitifera and A. muricata (246 bp), and the longest (422 bp) in Galaxea fascicularis (Table 3). Size differences in D2 domains introduced significant numbers of gaps for Acropora corals, and led to an alignment of up to $846 \mathrm{bp}$ among the 8 taxa (Figure 5).

Analysis of the $5^{\prime}$-end of LSU rDNA, including the D1 and D2 divergent domains, indicated that the divergence rate of the LSU rDNA differs between each taxonomic group of corals. First, the variability of aligned sequences was plotted for a series of overlapping 60-bp windows along the sequence from the $5^{\prime}$-end, including the D1 and D2 domains (Figure 6). The results of this analysis give a visual image of regional variability along the length of the sequences (Kumar et al., 1993). The following comparisons were carried out: among 3 species of Acropora, between 2 genera of Faviidae corals, between 2 genera of octocorals, between Acropora spp. and the other scleractinian genera, between Acropora spp. and Junceella fragilis, and between Acropora spp. and Virgularia juncea. In the 6 comparisons, the sequence divergences of both the D1 and D2 domains was high between in Acropora species (Figure 6, A), and even higher than that of 2 Faviidae corals at the generic level
Table 3. Size (bp) and $G+C$ Content of Two Divergent Domains (D1 and D2) in the $5^{\prime}$-End of LSU rDNA

\begin{tabular}{lllc}
\hline Taxon & $\begin{array}{l}5^{\prime} \text {-End of } \\
\text { LSU rDNA }\end{array}$ & $\begin{array}{c}\mathrm{D} 1 \\
(\% \mathrm{G}+\mathrm{C})\end{array}$ & $\begin{array}{c}\mathrm{D} 2 \\
(\% \mathrm{G}+\mathrm{C})\end{array}$ \\
\hline $\begin{array}{l}\text { Octocorallia } \\
\text { Junceella fragilis }\end{array}$ & 760 & $157(51)$ & $410(62.7)$ \\
$\quad$ Virgularia juncea & 769 & $158(51.8)$ & $418(65.3)$ \\
Scleractinia & & & \\
Acropora digitifera & 604 & $162(68.6)$ & $246(69.1)$ \\
Acropora muricata & 596 & $155(70.4)$ & $246(69.1)$ \\
Acropora cytherea & 616 & $161(71.6)$ & $260(65.7)$ \\
Galaxea fascicularis & 772 & $157(71.4)$ & $422(71.8)$ \\
Platygyra sinensis & 759 & $157(58)$ & $409(67)$ \\
Favites abdita & 756 & $157(57.3)$ & $406(65.5)$ \\
& & &
\end{tabular}

(Figure 6, B). Between 2 octocorallian genera, representing 2 families, the divergence was moderate (Figure 6, C). However, comparisons between Acropora spp. and the remaining taxa all showed extremely high divergences (Figure 6, D-F), with the highest one located at the $5^{\prime}$-end of the D2 domain among scleractinian genera (Figure 6, D).

Second, we analyzed the nucleotide composition focusing on 352 bp of the $5^{\prime}$-end of LSU rDNA. In this region, nucleotide frequencies did not differ significantly among coral species $\left(\chi^{2}\right.$-test, $\left.P<0.05\right)$; the transition-totransversion ratio estimated from the data set was $1.37 \pm$ 0.24. Pairwise comparisons of ML distances (Table 4) reflected similar patterns from the 60-bp sliding windows analyses. Among Acropora species, the ML genetic distances were relatively small with a mean of $0.0338(0.01926-$ 0.04425), but higher than that between Platygyra sinensis and Favites abdita (0.02554) at the generic level. The distances between Acropora and the other 3 genera of scleractinian corals were dramatically higher (0.27172-0.35346), and are comparable to those between Acropora and the 2 octocorals (0.393-0.47391).

Third, phylogenetic analyses of $205 \mathrm{bp}$ of the $5^{\prime}$-end of LSU rDNA sequences using maximum likelihood produced the same topology as neighbor-joining criteria (Figure 7). The branch length of the Acropora clade (0.418789) estimated with the HKY model was significantly longer than that of the scleractinian clade (0.19564), indicating that the evolutionary rate of Acropora LSU rDNA had accelerated after divergence from the common ancestor of scleractinian corals. 
$[\rightarrow D 1$

Junceella fragilis Virgularia juncea Acropora digitifera Acropora muricata Acropora cytherea Galaxea fascicularis Platygyra sinensis Favites abdita

Junceella fragilis Virgularia juncea Acropora digitifera Acropora muricata Acropora cytherea Galaxea fasciculari Platygyra sinensis Favites abdita

Junceella fragilis Virgularia juncea Acropora digitifera Acropora muricata Acropora cytherea Galaxea fascicularis Platygyra sinensis Favites abdita

Junceella fragilis Virgularia juncea Acropora digitifera Acropora muricata Acropora cytherea Galaxea fascicularis Platygyra sinensis Favites abdita

Junceella fragilis Virgularia juncea Acropora digitifera Acropora muricata Acropora cytherea Galaxea fascicularis Platygyra sinensis Favites abdita

Junceella fragilis Virgularia juncea Acropora digitifera Acropora muricata Acropora cytherea Galaxea fascicularis Platygyra sinensis Favites abdita

Junceella fragilis Virgularia juncea Acropora digitifera Acropora muricata Acropora cytherea Galaxea fascicularis Platygyra sinensis Favites abdita

Junceella fragilis Virgularia juncea Acropora digitifera Acropora muricata Acropora cytherea Galaxea fascicularis Platygyra sinensis Favites abdita
CAGTAATGGCGAATGAAGAGGGAACAG-CTCAATTTTGAAATCTCCGTTGC---TTG----CAACGGCGAATTGTAGTTTCGAG--AAGTACTTTCCAGG

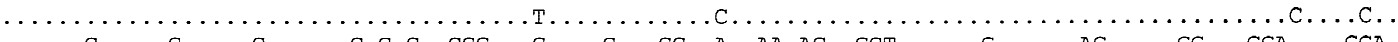

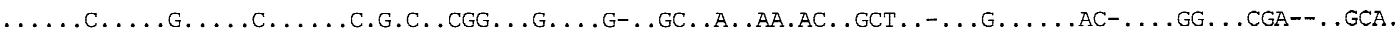

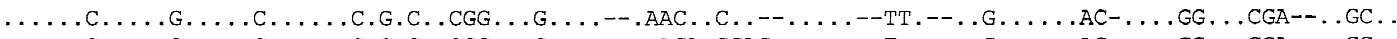

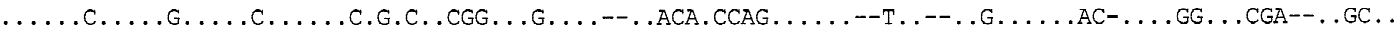

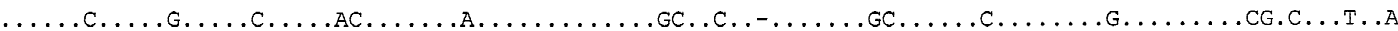

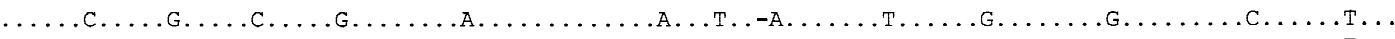

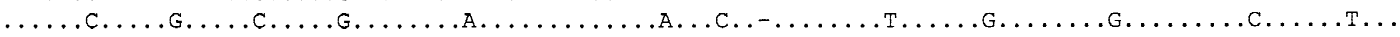

200 CGAA-CGGATCTTGCCTAAGTTGCTIGGAACAGCA-CGTCACAGAGGGTGACAACCCCGTACGTG---GCAAGGTC--CGTCGCTGGT--GAGG---TGC

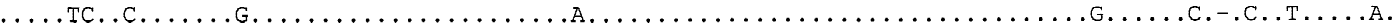
..GCG.C.TCGCC-T.CG...CT......G..-.G...GG..............T..C.AGG..-CC.A...G....-C..GC.-TCGATC. ..G.G.C.TCGCCCT.CG...CT......GG.-.G...GG...................AGG..GCC-A....G...-C.C.C.CTCGATC..

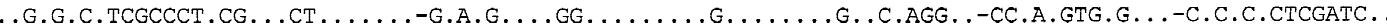

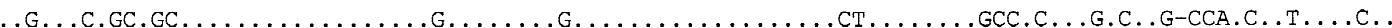

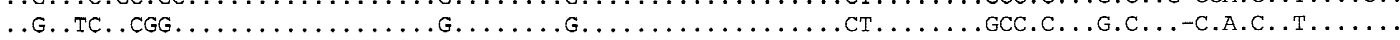

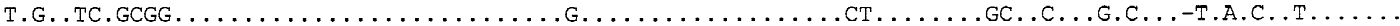

$D 1<---]$

TTTCATAGAGTCGGGTTGTTTGGGAATGCAGCCCAAA-ATGGGTGGTAAACTCCATCTAAAGCTAAATACAGG-CACGAGACCGATAGCGAACAAGTACC

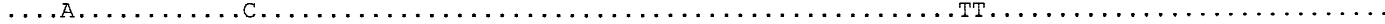

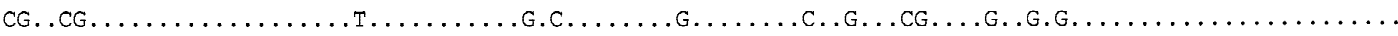

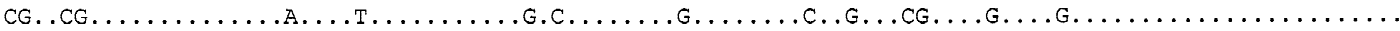

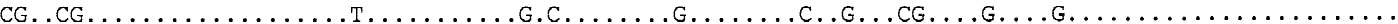

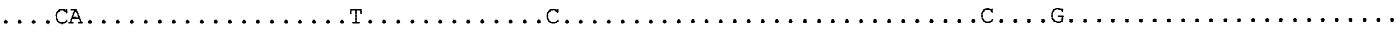

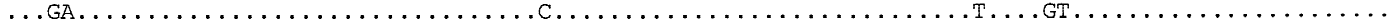

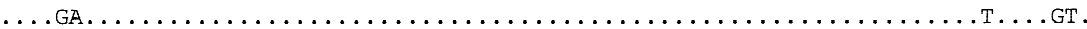

$[\quad-\rightarrow D 2$

400

GTGAGGGAAAGATGAAAAGGACTTTGAAAAGAGAGTTAAAAAGTACGTGAAACCGTTGAAAGGGAAGCGAATG-GAGTTAGCAATTCGCCCTGCCAGATT

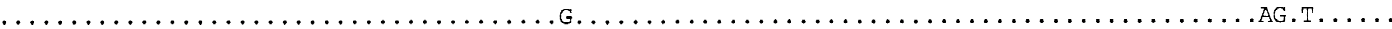

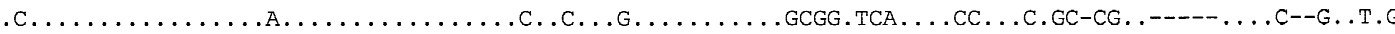

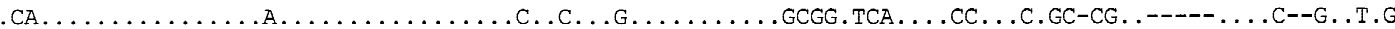

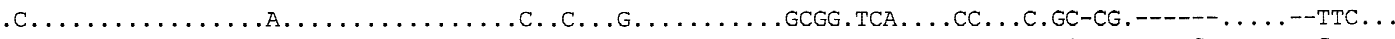

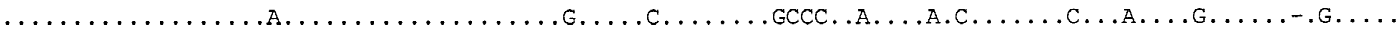

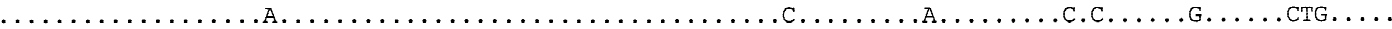

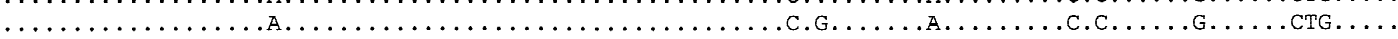

CAGTCTTAC-GCGTTCCG----CGACGGGC--GGCGCACTCGATCTACGTAGACGAGTCGTGTTCGG---ACGCGGCACG-GGAGAGGC---GCAT-TTA

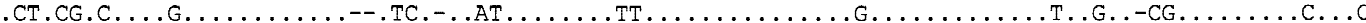

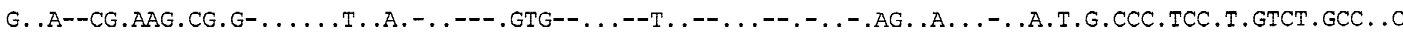

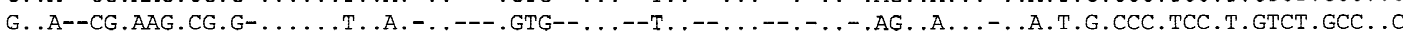
G.-A--CGGATG.CG.G.AC....G..T..TGTAA.GTG--...-T..-_...-.-..-.AG..A...-..A.T.G.CCC.TCC.T....T.GC.--C

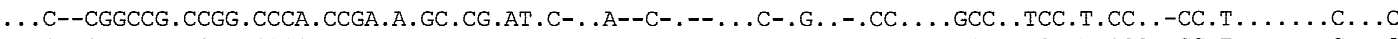

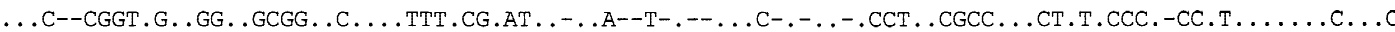

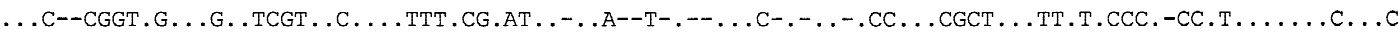

600

TGGCGGGCGAGCGTCAACGTCGGTCTTCGTC--GGGCTAAAAGG---CCGTGA-GGGAGGTGAACG-GC------CTT-CGGG------CC--GTTGTTA

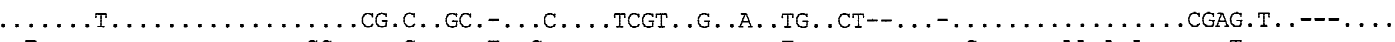
.T-

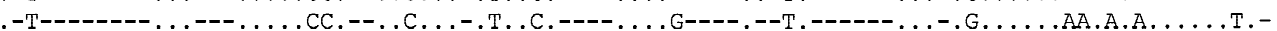

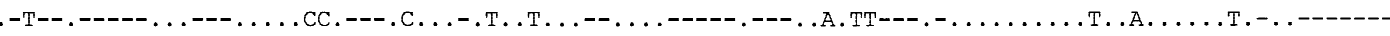

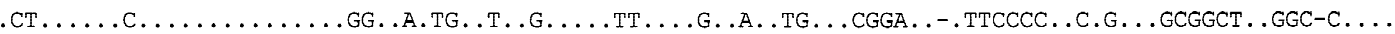

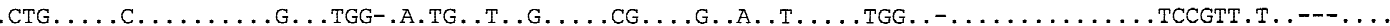

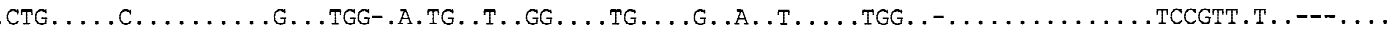

TAACCTCG---CGAGCGTATGGCTCGACGAAGACC-GTGGA-----GTCGCGAC----_---GCGTGCTT--CCCTCCGGGGGGGCTGGTGTCCTGTT--

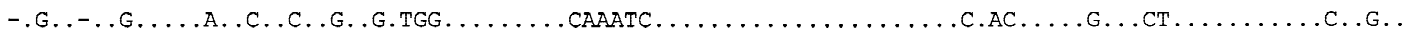

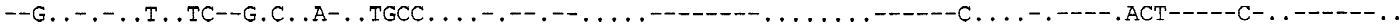

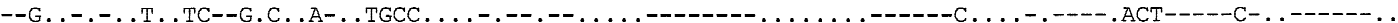

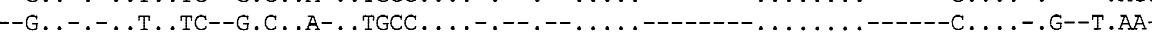

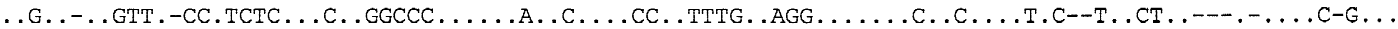

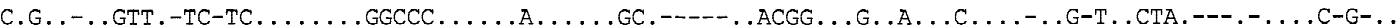

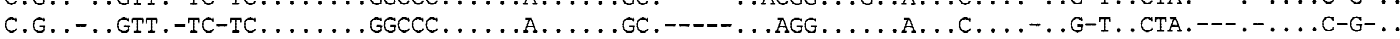

--CTGTTGGTCCGGTTGTCGACCGTGGCGGACGGCACGCCTGTGCGCTCGAACTGCTGCCGGTC-AACAGGGCGGTGAT-CACACACTACGCGTCGAGGA

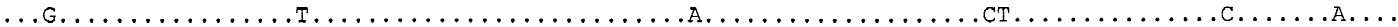
…-- . . А. . --- . С. . . . . . С.--- . T.A. .A.A.A-, .GA.T.

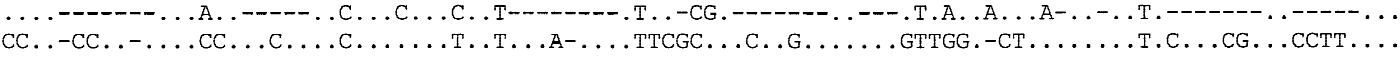

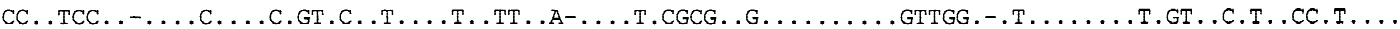
CC..-CC..-.........GT.C..T...T..TT..A-...T..GCG.AG.......GTTGG.-.T.....T.GT..C.T..CCTT...

Figure 5. 


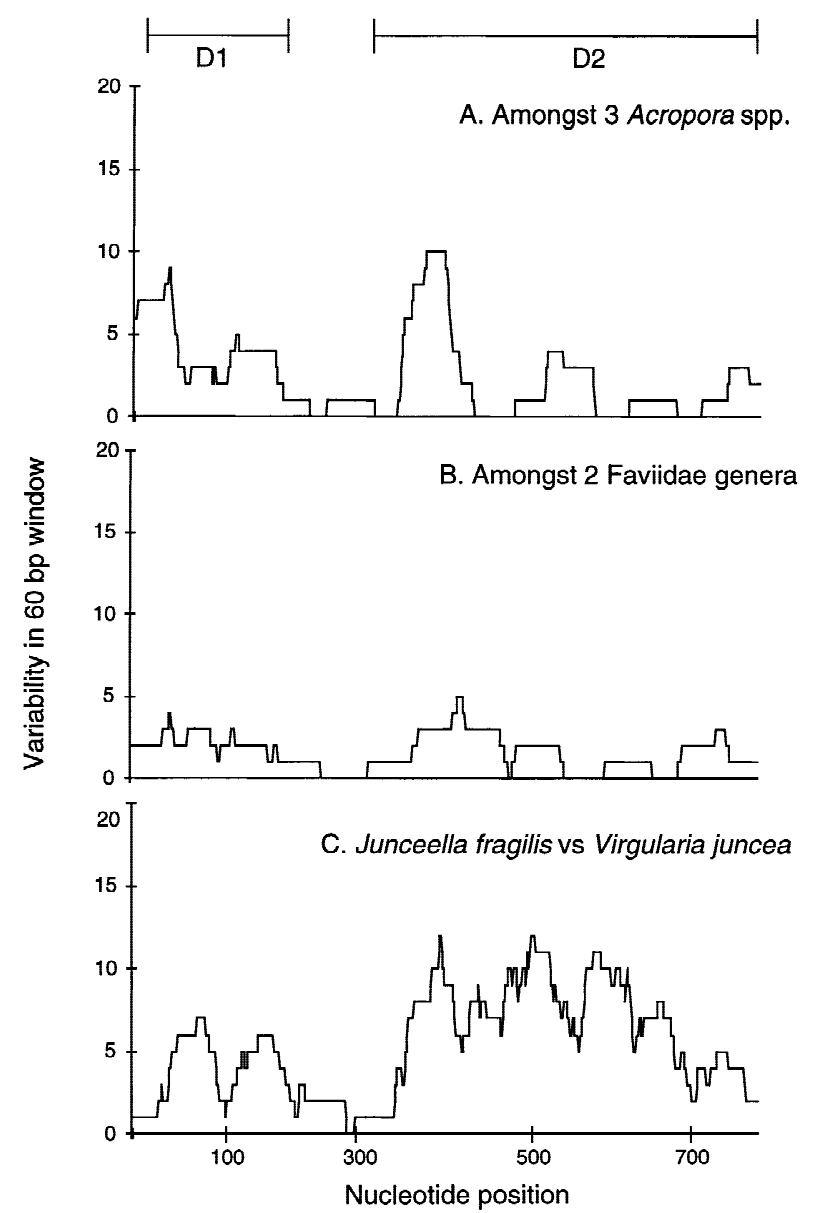

Figure 6. Variability in 60-bp sliding windows plotted throughout the $5^{\prime}$-end of the LSU rDNA region: among three Acropora spp. (A); among two Faviidae genera (B), Junceella fragilis versus Vir-

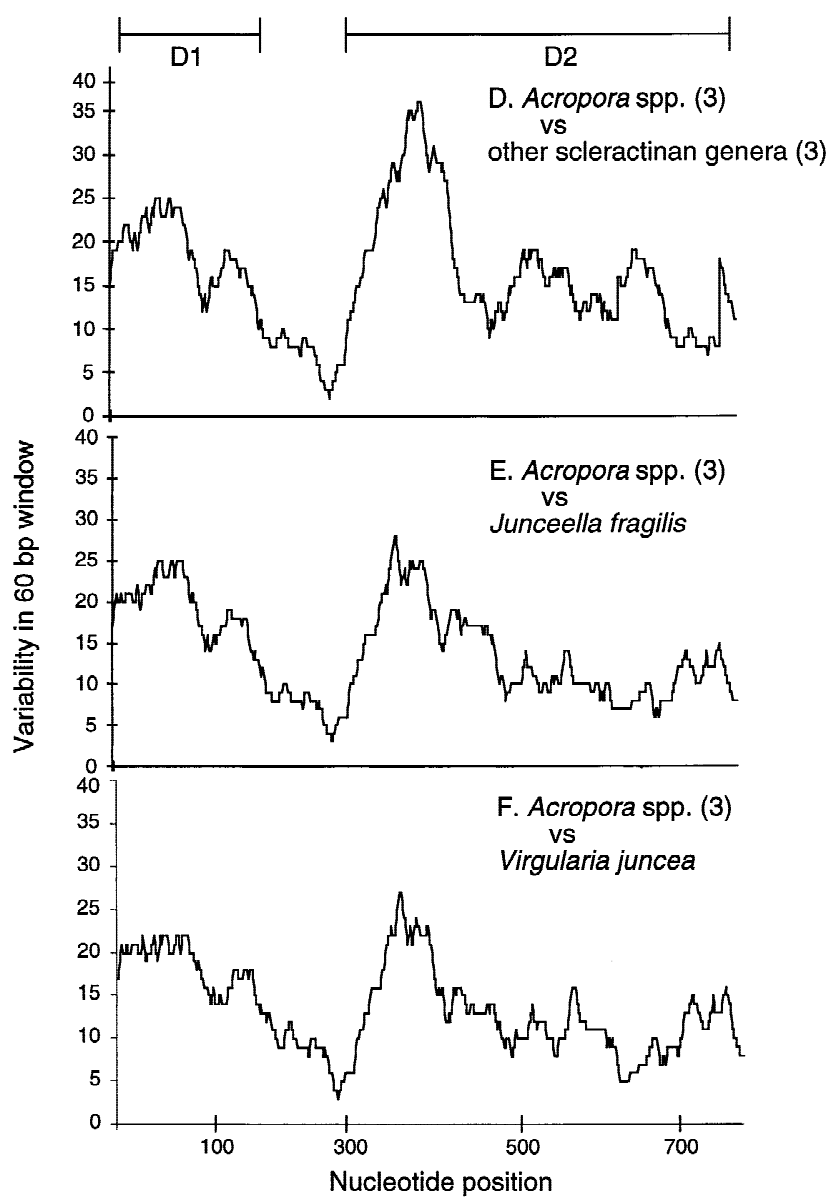

gularia juncea (C); Acropora spp. versus other scleractinian genera (D); Acropora spp. versus Junceella fragilis (E); and Acropora spp. versus Virgularia juncea (F).

Table 4. Maximum-Likelihood Distances Calculated Under the HKY Model (Hasegawa et al. 1985) in the Pairwise Comparison of 352 bp of the $5^{\prime}$-End of LSU rDNA Among the Eight Taxa of Corals*

\begin{tabular}{|c|c|c|c|c|c|c|c|}
\hline & JF & VJ & $\mathrm{AD}$ & $\mathrm{AF}$ & $\mathrm{AC}$ & PS & FA \\
\hline Virgularia juncea (VJ) & 0.05892 & & & & & & \\
\hline Acropora digitifera (AD) & 0.45824 & 0.42089 & & & & & \\
\hline Acropora muricata (AM) & 0.47391 & 0.43838 & 0.04425 & & & & \\
\hline Acropora cytherea (AC) & 0.45186 & 0.39300 & 0.03661 & 0.01926 & & & \\
\hline Favites abdita (FA) & 0.14666 & 0.14705 & 0.34792 & 0.35346 & 0.31407 & 0.02555 & \\
\hline Galaxea fascicularis (GF) & 0.22140 & 0.20840 & 0.30283 & 0.30742 & 0.27152 & 0.09072 & 0.09906 \\
\hline
\end{tabular}

${ }^{\star}$ Boldface indicates the interordinal and interfamilial comparisons between Acropora and other corals.

match repair system (Pont-Kingdon et al., 1998) may account for this unique phenomenon, although the actual repair system has not yet been identified in the Acropora mitochondrial genome. Unfortunately, repair mechanisms appear to be extremely complex, and our knowledge of them is far from complete (Page and Holmes, 1998). Therefore whether the lack of a functional repair system or an inefficient repair system in the nuclear genome causes the 


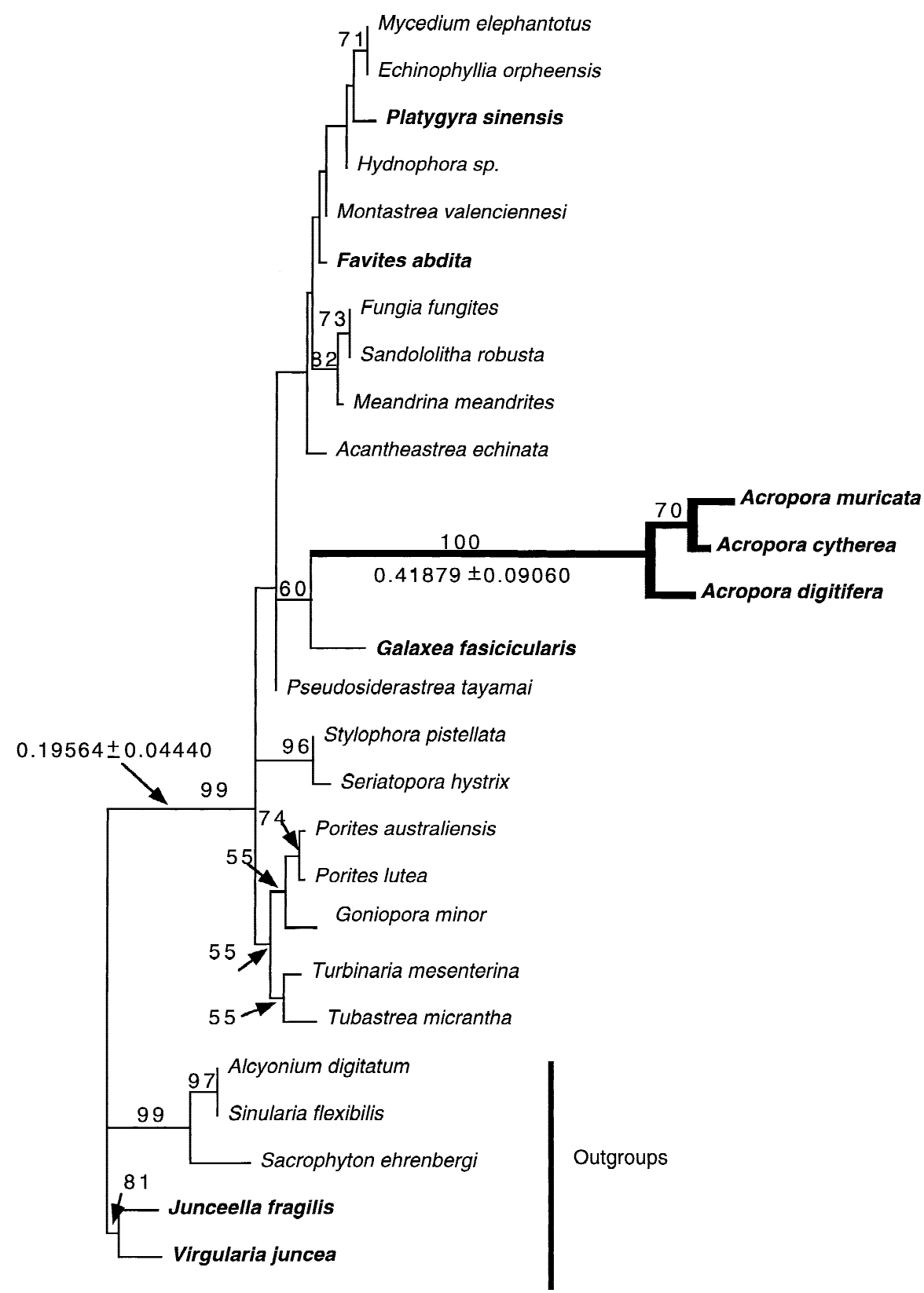

Figure 7. Phylogenetic analyses of $205 \mathrm{bp}$ of the 5 '-end of LSU rDNA sequences. The figure shows the tree inferred by the neighbor-joining method. Octocorallians assigned as outgroups are indicated by vertical bars. Branch lengths are proportional to evolutionary distances. A tree of the same topology was inferred by the maximum-likelihood method. Branch lengths and standard errors estimated by the maximum-likelihood method are indicated for those larger than 0.1 . The numbers above or below the branches leading to the nodes represent the percentage of 1000 bootstrap pseudoreplications that support the node in the neighbor-joining analysis. Bootstrap values less than $50 \%$ are not shown. LSU rDNA sequences obtained from this study are shown in boldface. GenBank accession numbers of coral 5 '-end LSU rDNA sequences were indicated as follows: Alcyonium digitatum, U69680; Sinularia flexibilis, U69681; Sacrophyton ehrenbergii, U69679; Stylophora pistillata, U65519; Seriatopora hystrix, U65520; Pseudosiderastrea tayamai, U65518; Acanthastrea echinata, U65524; Hydnophora sp., U65526; Mycedium elephantotus, U65527; Montastrea valenciennesi, U65525; Turbinaria mesenterina, U65513; Tubastrea micrantha, U65514; Goniopora minor, U65515; Porites australiensis, U65516; Porites lutea, U65517; Fungia fungites, U65523; Meandrina meandrites, U65521; and Sandalolitha robusta, U65522. high variability of rRNA genes in the genus Acropora remains equivocal.

An alternative hypothesis for the high rDNA sequence divergence in the genus Acropora is repeated recombination and crossing-over among Acropora species through past hybridization events (Kenyon, 1997; Odorico and Miller, 1997a, 1997b). Acropora is the largest extant genus of reefbuilding coral, with 113 species currently described (Wallace, 1999). Most species of Acropora are broadcast spawners, releasing eggs and sperm synchronously during mass spawning events (Harrison et al., 1984; Harrison and Wal- lace, 1990; Richmond and Hunter, 1990; Dai et al., 1992; C.A. Chen et al., unpublished data). Multispecies gamete slicks therefore form at the water surface, where fertilization takes place. The opportunity for hybridization is very plausible. In supporting this scenario, in vitro hybridization experiments have been successfully carried out between species within a genus, including the genus Acropora, as well as between species of different genera (Willis et al., 1997). Counting the somatic chromosome number in 22 species of Acropora, Kenyon (1997) proposed that the ability to propagate clones through vegetative fragmentation plus the 
opportunities for hybridization may have contributed to the development of polyploidy and rapid, sympatric speciation in the genus Acropora. Odorico and Miller (1997b) have demonstrated, at the molecular level, that the pattern of ITS variation is unusual. For example, 2 distinct ITS2 types were detected in both A. hyacinthus and A. cytherea, species known to hybridize in vitro with a high success rate (Willis et al., 1997); and a putative intermediate ITS2 form was also detected in A. cytherea, supporting the idea of reticulate evolution for the genus Acropora. Further investigation of sequence variation of the divergent domains within LSU rDNA from variety of Acropora spp. might provide potential evidence to support this scenario.

In conclusion, the nearly complete nuclear large subunit ribosomal RNA gene in corals was successfully amplified by primers designed by strategies of PCR. Analysis of the $5^{\prime}$-end of the LSU rRNA gene shows different divergence rates among the major taxonomic group of corals. The presence of a long branch of the Acropora clade from the other scleractinian corals in the phylogenetic tree indicates that the evolutionary rate of Acropora LSU rDNA accelerated after divergence from the common ancestor of scleractinian corals.

\section{ACKNOWLEDGMENTS}

Many thanks to the staff of the Penghu Aquarium, a facility of the Taiwan Fishery Research Institute, for providing assistance during coral spawning in 1998 and 1999. We thank J. Wolstenholme and members of the Evolution and Ecology Discussion Group, Institute of Zoology, Academia Sinica (IZAS), for constructive comments before submission. This is Evolution and Ecology Group, IZAS Contribution No. 5. This work was supported by grants from IZAS, the National Science Council, Republic of China (C.A.C), and the Australian Research Council (C.C.W).

\section{REFERENCES}

Aguinaldo, A.M.A., Turbeville, J.M., Linford, L.S., Rivera, M.C., Garey, J.R., Raff, R.A., and Lake, J.A. (1997). Evidence for a clade of nematodes, arthropods, and other moulting animals. Nature 387:489-493.

Berntson, E.A., France, S.C., and Mullineaux, L.S. (1999). Phylogenetic relationships within the class Anthozoa (Phylum Cnidaria) based on nuclear 18S rDNA sequences. Mol Phylogenet Evol 13: 417-433.

Braga, E., Zardoya, R., Meyer, A., and Yen, J. (1999). Mitochondrial and nuclear rRNA based copepod phylogeny with emphasis on the Euchaetidae (Calanoida). Mar Biol 133:79-90.

Bridge, D., Cunningham, C.W., DeSalle, R., and Buss, L.W. (1995). Class-level relationships in the phylum Cnidaria: molecular and morphological evidence. Mol Biol Evol 12:679-698.

Cedergren, R., Gray, M.W., Abel, Y., and Sankoff, D. (1988). The evolutionary relationships among known life forms. J Mol Evol 28:98-112.

Chen, C.A., and Yu, J.-K. (2000). Universal primers for amplification of mitochondrial small subunit ribosomal RNA-encoding gene in scleractinian corals. Mar Biotechnol 2:146-153.

Chen, C.A., Odorico, D.M., ten Louis, M., Veron, J.E., and Miller, D.J. (1995). Systematic relationships of the Anthozoa using 5 '-end of 28S rDNA. Mol Phylogenet Evol 4:175-183.

Chen, C.A., Miller, D.J., Wei, N.V., Dai, C.-F., and Yang, H.-P. (2000). The ETS/IGS region in a lower animal, the seawhip, Junceella fragilis (Cnidaria; Anthozoa; Octocorallia): compactness, low variation and apparent conservation of a pre-rRNA processing signal with fungi. Zool Stud 39:138-143.

Chombard, C., Boury-Esnault, N., and Tillier, S. (1998). Reassessment of homology of morphological characters in tetractinellid sponges based on molecular data. Syst Biol 47:351-366.

Dai, C.-F. (1989). The Corals of Taiwan. Taipei: Taiwan Provincial Department of Education, Taiwan, ROC.

Dai, C.F., Soong, K., and Fan, T.Y. (1992). Sexual reproduction of corals in northern and southern Taiwan. Proc 7th Coral Reef Symp 2:448-455.

De Rijk, P., Van de Peer, Y., Van den Broeck, I., and De Wachter, R. (1995). Evolution according to large ribosomal subunit RNA. J Mol Evol 41:366-375.

De Rijk, P., Caers, A., Van de Peer, Y., and De Wachter, R. (1998). Database on the structure of large ribosomal subunit RNA. Nucleic Acids Res 23:183-186.

Field, K.G., Olsen, G.J., Lane, D.J., Giovannoni, S.J., Ghiselin, M.T., Raff, E.C., Pace, N.R., and Raff, R.A. (1988). Molecular phylogeny of the animal kingdom. Science 237:748-753.

France, S.C., Rosel, P.E., Agenbroad, J.E., Mullineaux, L.S., and Kocher, T.D. (1996). DNA sequence variation of mitochondrial large-subunit rRNA provides support for a two-subclass organization of the Anthozoa (Cnidaria). Mol Mar Biol Biotechnol 5:1528.

Gerbi, S. (1985). Evolution of ribosomal RNA. In: Molecular Evo- 
lutionary Genetics, MacIntyre, R.J. (ed.). New York: Plenum, 419517.

Gilbert, D.C. (1994). SEQAPP 1.9. A biological sequence editor and analysis program for Macintosh computers. Available from ftp.bio.indiana.edu.

Hadfield, K.A., Swalla, B.J., and Jeffery, W.R. (1995). Multiple origins of anural development in ascidians inferred from rDNA sequences. J Mol Evol 40:413-427.

Harrison, P.L., and Wallace, C.C. (1990). Reproduction, dispersal and recruitment of scleractinian corals. In: Ecosystems of the World, Dabinsky, E. (ed.). New York: Elsevier, 133-196.

Harrison, P.L., Babcock, R.C., Bull, G.D., Oliver, J.K., Wallace, C.C., and Willis, B.L. (1984). Mass spawning in tropical reef corals. Science 223:1186-1189.

Hasegawa, M., Kishino, H., Yano, K. (1985). Dating of the humanage splitting by a molecular clock of mitochondrial DNA. J Mol Evol 22:160-174.

Hassouna, N., Michot, B., and Bachellerie, J.-P. (1984). The complete nucleotide sequence of mouse $28 \mathrm{~S}$ rRNA gene: implications for the process of size increase of the large subunit rRNA in higher eukaryotes. Nucleic Acids Res 12:3563-3583.

Hillis, D.M., and Doxon, M.T. (1991). Ribosomal DNA: molecular evolution and phylogenetic inference. Q Rev Biol 66:411-453.

Kenyon, J.C. (1997). Models of reticulate evolution in the coral genus Acropora based on chromosome. Evolution 51:756-767.

Kim, J., Kim, W., and Cunningham, C.W. (1999). A new perspective on lower metazoan relationships from $18 \mathrm{~S}$ rDNA sequences. Mol Biol Evol 16:423-427.

Kumar, S., Tamura, knowledge., and Nei, M. (1993). MEGA 1.01: Molecular Evolutionary Genetics Analysis. University Park: The Pennsylvania State University.

Lafay, B., Smith, A.B., and Christen, R. (1995). A combined morphological and molecular approach to the phylogeny of asteroids (Asteroidea: Echinodermata). Syst Biol 44:190-208.

Littlewood, D.T.J. (1994). Molecular phylogenetics of cupped oysters based on partial 28S rRNA gene sequences. Mol Phylogenet Evol 3:221-229.

Littlewood, D.T.J., Smith, A.B., Clough, K.A., and Emson, R.H. (1997). The interrelationships of the echinoderm classes: morphological and molecular evidence. Biol J Linn Soc 61:409-438.

Litvaitis, M.K., and Rohde, K. (1999). A molecular test of platyhelminth phylogeny: inference from partial $28 \mathrm{~S}$ rDNA sequences. Invert Biol 118:42-56.

Mallat, J., and Sullivan, J. (1998). $28 \mathrm{~S}$ and $18 \mathrm{~S}$ rDNA sequences support the monophyly of lampreys and hagfishes. Mol Biol Evol 15:1706-1718.

Michot, B., and Bachellerie, J.-P. (1987). Comparisons of large sub-unit rRNAs reveal some eukaryote-specific element of secondary structure. Biochemie 69:11-23.

Michot, B., Qu, L.-H., and Bachellerie, J.-P. (1990). Evolution of large sub-unit rRNA structure: the diversification of divergent D3 domain among major phylogenetic groups. Eur J Biochem 188: 219-229.

Nunn, G.B., Theisen, B.F., Christensen, B., and Arctander, P. (1996). Simplicity-correlated size growth of the nuclear 28 S ribosomal RNA D3 expansion segment in the crustacean order Isopoda. J Mol Evol 42:211-223.

Odorico, D.M., and Miller, D.J. (1997a). Internal and external relationships of the Cnidaria: implications of primary and predicted secondary structure of the $5^{\prime}$-end of the 23S-like rDNA. Proc R Soc London Biol Sci 264:77-82.

Odorico, D., and Miller, D.J. (1997b). Variation in the ribosomal internal transcribed spacers and 5.8S rDNA among five species of Acropora (Cnidaria: Scleractinia): variation consistent with reticulate evolution. Mol Biol Evol 14:465-473.

Page, R.D.M., and Holmes, E.C. (1998). Molecular Evolution: A Phylogenetic Approach. London, Blackwell.

Pont-Kingdon, G., Okada, N.A., Macfarlane, J.L., Beagley, C.T., Watkin-Sims, C.D., Cavalier-Smith, T., and Wholstenholme, D.R. (1998). Mitochondrial DNA of the coral Sarcophyton glaucum contains a gene for a homologue of bacterial MutS: a possible case of gene transfer from nucleus to the mitochondrion. J Mol Evol 46: 419-443.

Rho, B.-J., and Song, J.-I. (1976). A study on the classification of the Korean anthozoa, 1:Gorgonacea and Pennatulacea. J Korean Res Inst Better Living 17:71-92.

Richmond, R.H., and Hunter, C.L. (1990). Reproduction and recruitment of corals: comparisons among the Caribbean, the tropical Pacific, and the Red Sea. Mar Ecol Prog Ser 60:185-203.

Romano, S.L., and Palumbi, S.R. (1996). Evolution of scleractinian corals inferred from molecular systematics. Science 271:640-642.

Romano, S.L., and Palumbi, S.R. (1997). Molecular evolution of a portion of the mitochondrial $16 \mathrm{~S}$ ribosomal gene region in scleractinian corals. J Mol Evol 45:397-411.

Smith, C., Chen, C.A., Yang, H.P., and Miller, D.J. (1997). A PCR-based method for assaying molecular variation in corals based on RFLP analysis of the ribosomal intergenic spacer region. Mol Ecol 6:683-685.

Smothers, J.F., von Dohlen, C.D., Smith, H.S.I., and Spall, R.D. 
(1994). Molecular evidence that the myxozoan protists are metazoans. Science 265:1719-1721.

Steiner, G., and Müller, M. (1996). What can $18 \mathrm{~S}$ rDNA do for bivalve phylogeny? J Mol Evol 43:58-70.

Strimmer, K., and von Haeseler, A. (1996). Quartet puzzling: a quartet maximum likelihood method for reconstructing tree topologies. Mol Biol Evol 13:964-969.

Swofford, D.L. (1999). PAUP 4.03b: Phylogenetic Analysis Using Parsimony (and other methods). Sunderland, Mass.: Sinauer Associates.

Thompson, J.D., Higgins, D.G., and Gibson, T.J. (1994). CLUSTAL W: improving the sensitivity of progressive multiple sequence alignment through sequence weighting, position-specific gap penalties and weight matrix choice. Nucleic Acids Res 22:46734680 .

Van de Peer, Y., Neefs, J.-M., and De Wachter, R. (1990). Small ribosomal subunit RNA sequences, evolutionary relationships among different life forms, and mitochondrial origins. J Mol Evol 30:221-232.

Van de Peer, Y., Van de Broeck, I., and De Wachter, R. (1994). Database on the structure of small ribosomal subunit RNA. Nucleic Acid Res 22:3488-3494.

Van de Peer, Y., Jansen, J., De Rijk, P., and De Wachter, R. (1997). Database on the structure of small ribosomal subunit RNA. Nucleic Acid Res 25:111-116.

Van Oppen, M.J.H., Willis, B.L., and Miller, D.J. (1999). Atypically low rate of cytochrome $b$ evolution in the scleractinian coral genus Acropora. Proc R Soc Lond Biol Sci 266:179-183.

Vermeire, M.J. (1994). Reproduction and growth of a gorgonian sea whip, Junceella fragilis, in southern Taiwan. Master's thesis, National Taiwan University.
Veron, J.E.N. (1995). Corals in Space \& Time: The Biogeography \& Evolution of the Scleractinia. Sydney, NSW, Australia: UNSW Press.

Veron, J.E.N., and Pichon, M. (1980). Scleractinia of Eastern Australia, III: families Agaraciidae, Siderastreidae, Fungiidae, Oculinidae, Merulinidae, Mussidae, Pectiniidae, Caryophylliidae, Dendrophylliidae. Aust Inst Mar Sci Monogr Ser 5:471.

Veron, J.E., Pichon, M., and Wijsman-Best, M. (1977). Scleractinia of Eastern Australia, II: families Faviidae, Trachyphylidae. Aust Inst Mar Sci Monogr Ser 3:233.

Veron, J.E.N., Odorico, D.M., Chen, C.A., and Miller, D.J. (1996). Reassessing evolutionary relationships of scleractinian corals. Coral Reefs 15:1-9.

Wainright, P.O., Hinkle, G., Sogin, M.L., Stickel, S.K. (1993). Monophyletic origins of the metazoa: an evolutionary link with fungi. Science 260:340-342.

Walker, T.A., and Bull, G.D. (1983). A newly discovered method of reproduction in a gorgonian coral. Mar Ecol Prog Ser 12:137143.

Wallace, C.C. (1999). Staghorn Corals of the World: A Revision of the Coral Genus Acropora (Scleractinia; Astrocoeniina; Acroporidae) Worldwide, with Emphasis on Morphology, Phylogeny and Biogeography. Collingwood, NSW, Australia: CSIRO Publishing.

Willis, B.L., Babcock, R.C., Harrison, P.L., and Wallace, C.C. (1997). Experimental hybridization and breeding incompatibilities within the mating system of mass spawning reef corals. Coral Reefs 16(suppl):S53-S65.

Winnepenninckx, B., Backeliau, T., and De Wachter, R. (1996). Investigation of molluscan phylogeny on the basis of $18 \mathrm{~S}$ sequences. Mol Biol Evol 13:1306-1317.

Zardoya, R., and Meyer, A. (1996). Evolutionary relationships of the coelacanth, lungfishes, and tetrapods based on the $28 \mathrm{~S}$ ribosomal RNA gene. Proc Natl Acad Sci USA 93:5449-5454. 